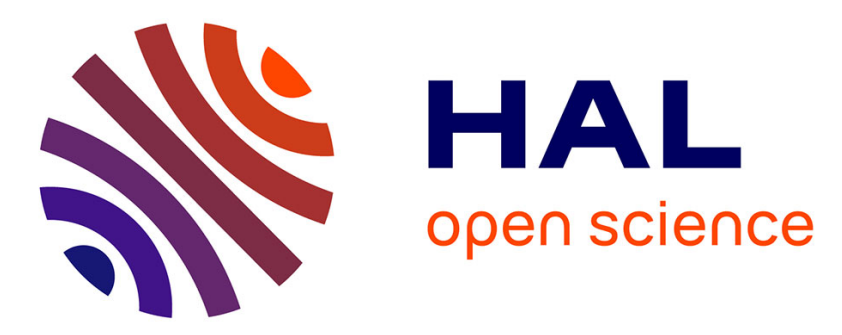

\title{
Substitution of Osteoporotic Alveolar Bone by Biphasic Calcium Phosphate/Poly-DL-lactide-co-glycolide Biomaterials
}

Zorica Ajduković, Nenad Ignjatović, Dragan Petrović, Dragan Uskoković

\section{- To cite this version:}

Zorica Ajduković, Nenad Ignjatović, Dragan Petrović, Dragan Uskoković. Substitution of Osteoporotic Alveolar Bone by Biphasic Calcium Phosphate/Poly-DL-lactide-co-glycolide Biomaterials. Journal of Biomaterials Applications, 2007, 21 (3), pp.317-328. 10.1177/0885328207073760 . hal-00570776

\section{HAL Id: hal-00570776 https://hal.science/hal-00570776}

Submitted on 1 Mar 2011

HAL is a multi-disciplinary open access archive for the deposit and dissemination of scientific research documents, whether they are published or not. The documents may come from teaching and research institutions in France or abroad, or from public or private research centers.
L'archive ouverte pluridisciplinaire HAL, est destinée au dépôt et à la diffusion de documents scientifiques de niveau recherche, publiés ou non, émanant des établissements d'enseignement et de recherche français ou étrangers, des laboratoires publics ou privés. 


\title{
Substitution of Osteoporotic Alveolar Bone by Biphasic Calcium Phosphate/Poly-DL- lactide-co-glycolide Biomaterials
}

\author{
Zorica AJduković, ${ }^{1}$ NenAD IGNJATOvić, ${ }^{2}$ \\ DRAGAN PETROVIĆ ${ }^{3}$ AND DRAGAN USKOKOVIĆ ${ }^{2, *}$ \\ ${ }^{1}$ Faculty of Medicine, Niš, Clinic of Stomatology \\ Department of Prosthodontics, Niš, Serbia and Montenegro \\ ${ }^{2}$ Institute of Technical Sciences of the Serbian \\ Academy of Sciences and Arts, Belgrade, Serbia and Montenegro \\ ${ }^{3}$ Faculty of Medicine, Niš, Clinic of Stomatology \\ Department of Maxillofacial Surgery, Niš, Serbia and Montenegro
}

\begin{abstract}
Lost bone tissue due to osteoporosis makes dentistry very difficult. The aim of this study is to reconstruct the bone tissue with composite biomaterials and to estimate the optical density and alveolar ridge height of the mandible. Research is conducted on 30 postmenopausal women aged from 46 to 62 years, with diagnosed osteoporosis and defects in alveolar bones caused by extraction of paradontopathic teeth, enucleation of cysts and periapical changes, extraction of impacted teeth, or by trauma. Biphasic calcium phosphate/poly-DL-lactide-co-glycolide (BCP/PLGA) composite is implanted into the defects of alveolar bones. Six weeks after implantation of BCP/PLGA, the alveolar bone density in the region of premolars on the experimental side of the jaw is found to be lower than that on the untreated, control, side of the jaw. On the contrary, 24 weeks after implantation, it is significantly higher compared with the density of the control side. A significant increase in optical density of alveolar bones in the region of premolars on the experimental side compared with the control one is noticed. These results indicate a high level of osteoregeneration and osteoblast activity. Synthetic BCP/PLGA composite belongs to the group of biomaterials, which facilitate formation of new bones
\end{abstract}

\footnotetext{
*Author to whom correspondence should be addressed. E-mail: uskok@itn.sanu.ac.yu
} 
and rehabilitation of alveolar bones weakened by osteoporosis. Because of its osteoconductive characteristics, BCP/PLGA composite is supposed to be the material of choice for replacement of bone tissue in the future.

KEY WORDS: osteoporosis, alveolar bone, reconstruction, biphasic calcium phosphate/poly-DL-lactide-co-glycolide (BCP/PLGA), biocomposites.

\section{INTRODUCTION}

$\mathbf{O}$ steoporosis is a systemic bone disease, characterized by reduction in bone volume per volume unit [1,2]. Bone provides support and stability to all types of dental implants and suprastructures. Therefore, problems with deossification caused by osteoporosis have been seriously addressed in stomatology [3-5], because any loss of bone tissue has as a consequence inadequate dentistry [5-7].

Numerous procedures for the reconstruction of alveolar bones have been reported. So far, repairs to alveolar bone defects have been made in monkeys, dogs, and rats [8-10]. In clinical studies, correction of alveolar deformities, height and width of alveolar ridges, has been made by destructive osteogenesis [11]. Some authors have reported on porous, $\beta$ tricalcium phosphates ( $\beta$-TCP) used as filler for large alveolar defects of the mandible after enucleation of residual cysts, to achieve regular alveolar ridge height so that dental implants can be easily inserted [12].

In order to solve the problem of bone tissue loss caused by advanced resorption of alveolar bone due to systemic osteoporosis, we have used a biphasic calcium phosphate/poly-DL-lactide-co-glycolide (BCP/DLPLG) composite biomaterial [13]. The most important characteristic of biphasic calcium phosphate is its chemical similarity to the mineralized bone phase, while bioresorbable polymers based on lactide and glycolide exhibit a high degree of biocompatibility and nontoxicity [14-16]. Synthetic BCP/PLGA composite belongs to the group of biomaterials, which induce easier formation of new bones, and due to its osteoconductive potential it can successfully replace the bone tissue [17].

In previous work [13], the artificial defects in mandibles of rats damaged by osteoporosis were filled with BCP/PLGA biocomposite in order to reconstruct them. As BCP/PLGA in these investigations proved to be an extremely good osteoconductive biomaterial in osteoreconstructive processes, it was then used in clinical research.

The aim of this study is to investigate the possibility of reconstructing the bone tissue using calcium phosphate/poly-DL-lactide-co-glycolide composite biomaterial and to repair alveolar bones of patients affected by osteoporosis. The results of these applications were analyzed during the postoperative period by measuring relative optical densities of bone 
tissues and the heights of alveolar ridges. The novelty, compared to previous studies, is the reconstruction of alveolar bones of patients with diagnosed osteoporosis. The reparative ability of BCP/PLGA to restore the deformed alveolar ridge and the structure of prosthetic supporting tissue, which plays the primary role in the formation of prosthetic suprastructure, i.e., insertion of dentures that are to recover lost esthetic, phonetic, and masticatory functions, was examined.

\section{MATERIALS AND METHOD}

The used BCP/PLGA composite was synthesized according to the procedure given earlier $[13,18]$. Calcium phosphate gel was obtained by precipitation of calcium nitrate and ammonium phosphate in an alkaline medium. It was dried at room temperature and then calcined at $1100^{\circ} \mathrm{C}$ for $6 \mathrm{~h}$. Poly-DL-lactide-co-glycolide (PLGA) (50:50) (Sigma Chemical Co., St. Louis, USA) was used as a polymer component. Into completely dissolved polymer, calcium phosphate granules (80 mass percent) were added. After stirring ( $30 \mathrm{rev} / \mathrm{min}$ ), methanol was added to the solution. Then, the solvent was removed and the particles were dried at room temperature for $24 \mathrm{~h}$. Composite biomaterial particles $0.153-0.2 \mathrm{~mm}$ in size were sieved and sterilized by $\gamma$-rays $(25 \mathrm{kGy})$ before use.

Upper and lower jaw tissue of 30 postmenopausal women aged 46-62 years was studied. After having been diagnosed with periapical lesions, impacted teeth, and cysts in alveolar bones, the patients were prepared for surgery (mucoperiosteal flap was lifted, pathologic changes eliminated, and the lost bone tissue replaced with BCP/PLGA composite). Then, the diagnosed parodontopathic teeth in the premolar or molar region were extracted and the extraction wounds filled with BCP/PLGA composite. One side of the jaw (the experimental one), A, was filled with BCP/PLGA composite, while the other, contralateral one, served as the control side, $\mathrm{B}$.

Radiological analysis included radiography of jaws by orthopanthomographical method. Density and height of alveoli were analyzed in the regions of premolars and molars, i.e., regions from which pathologic tissue was removed. The heights of these regions, from the lower edge of the jaw to the upper edge of the defect, were measured by a Manser (Inox) ruler (nonius). The relative optical density was measured in an area $14 \mathrm{~mm}$ in diameter around the defect. Each orthopanthomogram had a fixed, transparent, thermo-stable celluloid foil with a printed net of squares $\left(2 \times 2 \mathrm{~mm}^{2}\right)$. On each foil, regions of first premolars and molars were marked. A light beam from a densitometer DT II 05 (London, Great Britain) was passed through each segment of the 
orthopanthomograph. Numerical values of the relative optical densities were calculated and statistically analyzed. After consolidation and healing of wounds, fixed or mobile dentures, depending on the state of the prosthetic supporting tissue and the number and condition of the remaining teeth, were inserted. The patients were observed during a period of $6-24$ weeks.

The statistical significance of differences was analyzed by Student's $t$-test.

\section{RESULTS AND DISCUSSION}

As already mentioned, patients' bones weakened by osteoporosis were reconstructed with BCP/PLGA composite (Figure 1). Osteoporosis was diagnosed by a densitometer [19] and also by blood biochemical analyses. The obtained results for calcium of $1.8 \mathrm{mmol} / \mathrm{L}$, phosphorus of $0.69 \mathrm{mmol} / \mathrm{L}$, and alkaline phosphatase of $58.1 \mathrm{IU} / \mathrm{L}$ confirmed the disease.

A composite production procedure via a solvent-non-solvent system provides covering of BCP particles with DLPLG polymer. Figure 1 shows SEM images of BCP/PLGA composite particles. As evident, BCP granules with an average particle diameter of $0.15-0.20 \mathrm{~mm}$ are coated with the polymer [13,18]. The principal idea of application is that, after implantation of the composite biomaterial into the bone defect, the polymer component (PLGA) that reinforces BCP bioresorbs thus

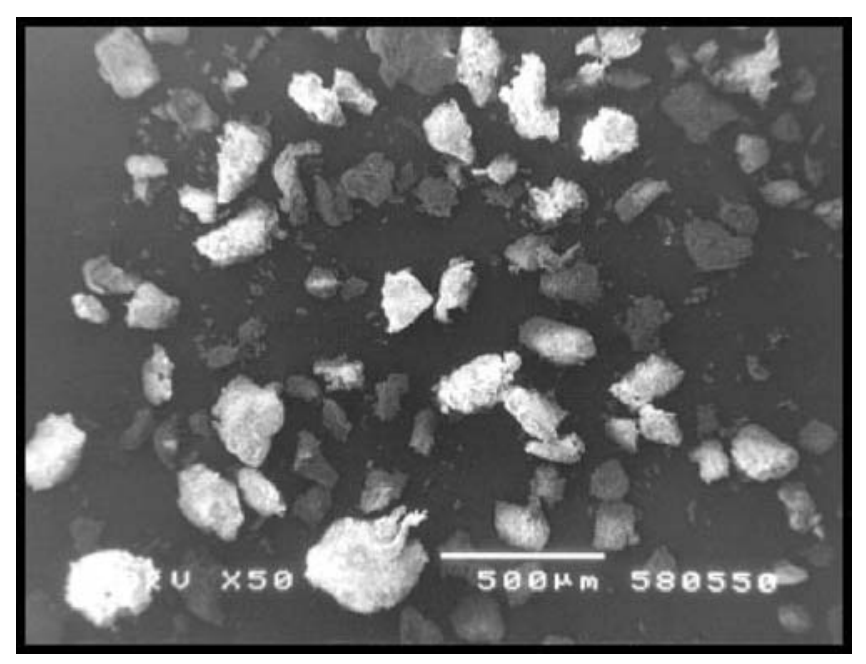

Figure 1. SEM images of BCP/PLGA composite biomaterial particles. 
relinquishing its place to the new-formed tissue. The BCP : PLGA mass ratio in the composite is $80: 20$, respectively, representing at the same time BCP:PLGA $=60: 40$ volume ratio. Natural bone tissue consists of $60 \mathrm{vol} \%$ of inorganic component (calcium phosphate) and $40 \mathrm{vol} \%$ of organic component (of a collagen type).

$\mathrm{BCP} / \mathrm{PLGA}$ was implanted in the premolar or molar region of the experimental side of the jaw (A), while the control, contralateral, side (B) (also premolar or molar region) was healthy and untreated. Analyses (measurement of alveolar ridge height and relative optical density) were made around the center of defects $14 \mathrm{~mm}$ in diameter; the same was carried out on the control side. Differentiation can also be made between the existing and newly-formed bone on the basis of the degree of their illumination. Newly formed bone, after implantation of BCP/PLGA is surrounded by a halo.

The healthy, control, side of the jaw is denoted in all figures by an arrow and letter B. The experimental side is denoted by A.

After impacted canine tooth and odontoma (shown in Figure 2(a)) had been diagnosed, the patient was prepared for the preprosthetic surgical

(a)

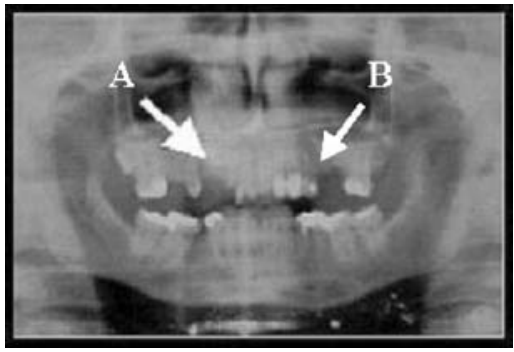

(c)

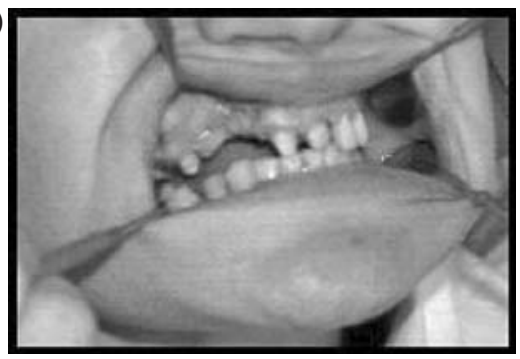

(b)

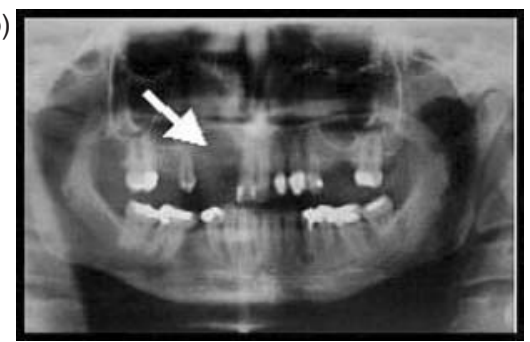

(d)

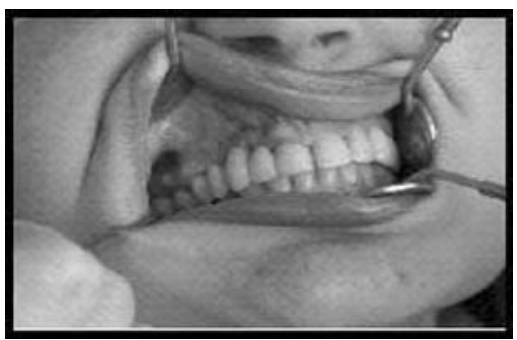

Figure 2. Rehabilitation of defects in the alveolar bone of maxilla: (a) the presence of impacted canine and odontoma in the region of first premolars ( $\mathrm{A}$ - experimental side, $\mathrm{B}$ - control side); (b) formation of new bone tissue after extraction of impacted tooth and odontoma, and implantation of BCP/PLGA into the generated defect; (c) consolidation of prosthetic supporting tissue; and (d) inserted fixed, upper denture. 
(a)

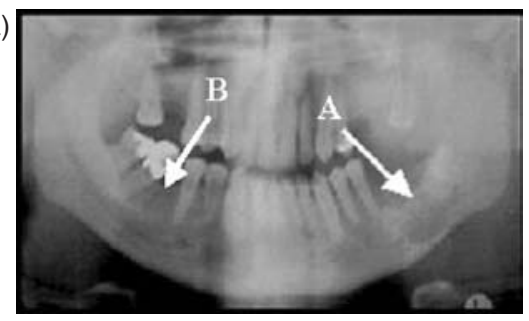

(c)

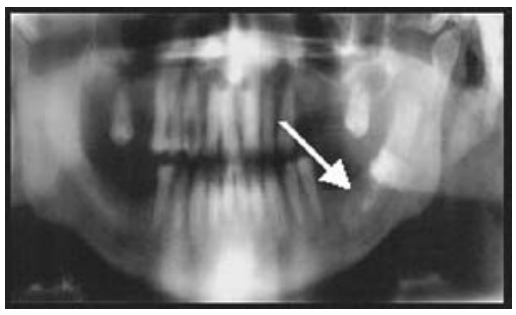

(b)

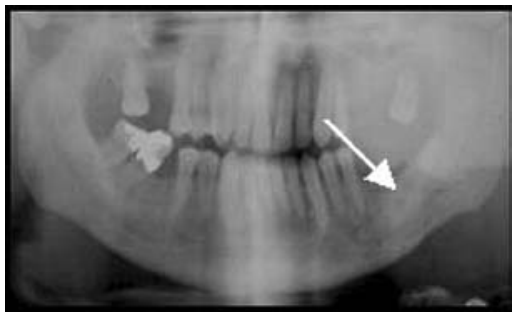

(d)

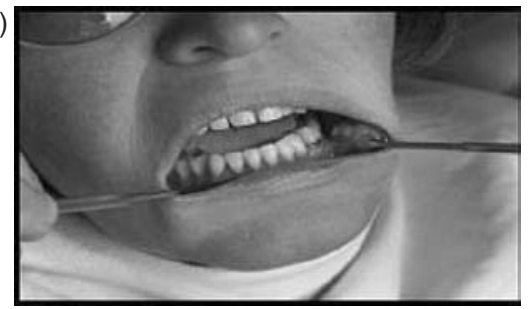

Figure 3. Rehabilitation of defects in the alveolar bone of the mandible: (a) a cyst in the alveolar bone of the mandible in the molar region (A - experimental side, $\mathrm{B}$ - control side); (b) formation of new bone tissue after cyst enucleation and implantation of BCP/ PLGA into the generated defect; (c) consolidation of prosthetic supporting tissue of the mandible; and (d) insertion of a mobile, partial, lower denture.

treatment (extraction of impacted tooth with odontoma and replacement of the lost bone tissue with BCP/PLGA composite). Twenty-four weeks after implantation, intensive osteogenesis, formation of new bone tissue very similar to the normal tissue of the control jaw side, as well as an increase in relative optical density and alveolar ridge height can be seen in Figure 2(b). After healing of the wound and bone tissue consolidation (Figure 2(c)), a fixed denture (Figure 2(d)) satisfying aesthetic, phonetic, and masticatory functions was inserted.

A cyst in the molar region of the alveolar bone of the mandible can be seen in Figure 3(a). Six weeks after enucleation of the cyst and implantation of BCP/PLGA, the formation of new bone tissue as well as a slight increase in optical density and alveolar ridge height, which is statistically still considerably lower than those of the control side of the jaw, can also be seen (Figure 3(b)). Twenty-four weeks after surgery, the formation of new bone tissue, initiated by intensive osteoregenerative processes, very similar to the tissue of the control side of mandible, as well as an increase in relative optical bone density and alveolar ridge height, is evident as shown in Figure 3(c). After healing of the wound and consolidation of the prosthetic supporting tissue, a mobile denture 
Table 1. Values of relative optical densities and alveolar ridge heights in the region of premolars.

\begin{tabular}{lccc}
\hline & & \multicolumn{2}{c}{ Experimental side of jaw $(\mathrm{A})$} \\
\cline { 3 - 4 } Variable & $\begin{array}{c}\text { Control side } \\
\text { of jaw }(\mathrm{B})\end{array}$ & $\begin{array}{c}\text { 6 weeks after } \\
\text { implantation }\end{array}$ & $\begin{array}{c}\text { 24 weeks after } \\
\text { implantation }\end{array}$ \\
\hline Number of patients & 30 & 30 & 30 \\
Relative optical density $\left(\mathrm{g} / \mathrm{cm}^{2}\right)^{*}$ & $1.078 \pm 0.144$ & $0.865 \pm 0.011$ & $1.263 \pm 0.150$ \\
Height of alveolar bone $(\mathrm{cm})^{*}$ & $2.60 \pm 0.16$ & $2.52 \pm 0.14$ & $2.91 \pm 0.19$ \\
\hline
\end{tabular}

was inserted (Figure 3(d)), which met prosthetic and functional requirements successfully.

The values summed up in Table 1 reveal a statistically significant decrease in optical density of alveolar bone in the region of premolars on the experimental side of the jaw (A) contrary to the density of the control side $(\mathrm{B})(P<0.01)$ six weeks after implantation of BCP/PLGA. These relative optical density values indicate the beginning of osteogenesis in alveolar bones weakened by osteoporosis, but they are still much lower than those of the control, untreated sides of jaws, due to insufficient time for bone tissue regeneration. In the 24th week (according to Figure 2(b)), a significant increase in optical density of the alveolar bone in the premolar region of the experimental side (A) contrary to the control side $(\mathrm{B})(P<0.05)$ can be seen. This confirms prevalence of osteoregenerative processes, increased activity of osteoblasts [20], decrease in atrophy and resorption, and improvement in prosthetic supporting tissue after implantation of the BCP/PLGA composite and adequately inserted dentures. Atrophy and resorption of the alveolar bone, which can be caused by systemic osteoporosis, other reasons, or diseases, present a serious problem in prosthetic rehabilitation. To solve this problem, porous hydroxyapatite granules together with polyglactin $910^{\circledR}$ have been used by some authors, who, applying the vestibuloplastic method, obtained satisfactory results [21].

Six weeks after implantation of BCP/PLGA, the analyzed alveolar ridge heights in the premolar regions on the experimental sides (A) taken from orthopanthomographs are lower than those of the control sides (B), but these differences are statistically insignificant (Table 1). Disturbances in bone metabolism in the premolar region are of lower intensity than those in the molar region, because this part of the jaw is subjected to less loads than the molar region, so that the rehabilitation is much faster for the same period. A slight increase in bone tissue resorption (as a self-protection reaction of the organism) was also 
Table 2. Values of relative optical density and alveolar ridge heights in the region of molars.

\begin{tabular}{lccc}
\hline & & \multicolumn{2}{c}{ Experimental side of jaw (A) } \\
\cline { 3 - 4 } Variable & $\begin{array}{c}\text { Control side } \\
\text { of jaw }(\mathrm{B})\end{array}$ & $\begin{array}{c}6 \text { weeks after } \\
\text { implantation }\end{array}$ & $\begin{array}{c}\text { 24 weeks after } \\
\text { implantation }\end{array}$ \\
\hline Number of patients & 30 & 30 & 30 \\
Relative optical density $\left(\mathrm{g} / \mathrm{cm}^{2}\right)^{*}$ & $1.084 \pm 0.004$ & $0.916 \pm 0.010$ & $1.193 \pm 0.150$ \\
Height of alveolar bone $(\mathrm{cm})^{*}$ & $2.98 \pm 0.20$ & $2.63 \pm 0.14$ & $3.24 \pm 0.20$ \\
\hline
\end{tabular}

observed during the first 6 weeks after implantation of the biocomposite, but soon after that osteogenesis prevailed. Twenty-four weeks after implantation and treatment of patients with adequate dentures, a statistically significant increase in heights of alveolar ridges in the premolar regions on the experimental sides of jaws (A) compared with the control ones $(\mathrm{B})(P<0.01)$ was observed. Also, a faster consolidation and healing of wounds after extraction were noticed. These results indicate the positive effects of combined treatments: the implantation of $\mathrm{BCP} / \mathrm{PLGA}$ composite and the use of adequate dentures.

During the six weeks after implantation of the biocomposite, a trabecular network was formed with collagen as the main structural protein, but six weeks is too short a period for deposition of a significant amount of inorganic salts and formation of good quality bone. In the beginning, BCP/PLGA composite causes a slow deposition of hydroxyapatite crystals, which follow collagen fibers orientation, while faster and better quality bone formation rich in inorganic components was observed 24 weeks after implantation of BCP/PLGA. Therefore, the relative optical density and alveolar ridge height, six weeks after implantation, are statistically significantly lower than those of the control side of the jaw, but 24 weeks after implantation of BCP/PLGA they are statistically much higher compared with the density and height of the control side, which is in agreement with the previous results.

Table 2 summarizes the values of densities and heights of alveolar ridges in the molar regions. A statistically significant decrease in optical densities of bones in the molar regions on the experimental sides of jaws (A), contrary to those of the control sides $(B)(P<0.01)$, can be seen 6 weeks after BCP/PLGA implantation. These values indicate already started rehabilitation and osteogenesis of tissues damaged by osteoporosis, but they are still much lower than the values obtained for the control sides (Figure 3(b)). Disturbed bone metabolism was 
first registered in the regions around lower molars, where stresses during mastication are the most pronounced, the reason why 6 weeks is an insufficient period for the regeneration and increase in density of such a loaded bone tissue. In the 24th week, a significant increase in relative optical densities of bones in the molar regions of the experimental (A) contrary to the control sides $(\mathrm{B})(P<0.05)$ is observed. The results indicate a significant increase in intensity of regenerative processes in the alveolar bone that lead to the reconstruction of the alveolar ridge, which is in accordance with the results obtained by some authors who studied deproteinized beef bone, xenograft, and osteosynthesis, but taking into account trabecular bone volume, jaw region, and the sex of patients [22-25]. Our results show an improved structure as well as quality of the alveolar bone affected by osteoporosis (as can be seen in Figure 3(c)), because after implantation of BCP/PLGA composite, incremental advances in new-formed vascular tissue, increased activity, and adherence of osteoblasts capable of providing much faster reparative processes in the bone affected by osteoporosis took place. All these led to improved prosthetic supporting tissue and successfully inserted dentures (Figure 3(d)).

The effects of mentioned treatments (implantation of the BCP/PLGA composite and insertion of adequate dentures) induced an increase in osteoblast activity, improvement in the structure and quality of the alveolar bone affected by osteoporosis, as well as local increase in bone density and alveolar ridge height in the premolar or molar region, where the composite had been implanted. By providing patients with adequate dentures, resorption in the regions subjected to increased stress was avoided, while increased activity of osteoblasts and rebuilding of alveolar bones prevailed. Similar results were obtained by other authors who reconstructed alveolar ridges using other implant materials [5,21,26]. The use of resorbable BCP/PLGA biomaterials facilitated the growth of newly formed vascular tissue, fibroblasts, and increased activity and adhesion of osteoblasts [27].

Alveolar bone is the most unstable paradoncium tissue and belongs to the group of the most dynamic human tissues, constantly rebuilding or being resorbed, which is a result of its adaptation to the homeostatic and mechanical needs of the organism [1,3,4]. Lower values of blood biochemical parameters, especially alkaline phosphatase, indicate lower osteoblast activity, retardation of anabolic processes, and appearance of osteoporosis. When depositing bone matrix, osteoblasts secrete small quantities of alkaline phosphatase, which causes a decrease in local concentration of inorganic phosphate, inhibition of collagen fiber activity, and decreased deposition of calcium salts [28]. Loss of the 
residual alveolar ridge usually connected with systemic or local osteoporosis, paradontal diseases, surgical procedures, tooth extraction, or congenital defects can lead to permanent deformities. During cicatrization of the defects, soft tissue usually collapse into them. The consequences of such a cicatrization are inadequate dentures, both functionally and aesthetically; in some cases it is even impossible to insert them. Therefore, correction of the alveolar ridge during tooth extraction or preprosthetic surgical preparations, before inserting dentures, provides optimal results in prosthetic rehabilitation. Application of bioresorbable BCP/DLPLG composite biomaterial facilitates generation of new bone tissue and its penetration through the very material, which leads to successful prosthetic treatment.

\section{CONCLUSION}

Based on investigations carried out, it can be concluded that BCP/ PLGA, 6 weeks after its implantation in the premolar and molar region of the experimental side of the jaw, causes a decrease in optical density and height of alveolar ridges of patients. In the 24th week, however, a significantly higher optical density and greater alveolar ridge height in the premolar and molar region on the side where the composite was implanted, compared with the control one, was found. The obtained results also indicate a more intensive osteoregenerative process and high level of osteoblast activity on the side where the composite was implanted. With increasing osteogenesis, in alveolar bones weakened by osteoporosis, the density of bone increases, so that the quality of the prosthetic supporting tissue after implantation of the composite is improved and can bear the dentures inserted.

\section{REFERENCES}

1. won Wowern, N., Klausen, B. and Kollerup, G. (1994). Osteoporosis: A Risk Factor in Periodontal Disease, J. Periodontol., 65: 1134-1138.

2. Klemetti, E. (1996). A Review of Residual Ridge Resorption and Bone Density, J. Prosthet. Dent., 75: 512-514.

3. Ravn, P., Neugebauer, G. and Christiansen, C. (2002). Association between Pharmacokinetics of Oral Ibandronate and Clinical Response in Bone Mass and Bone Turnover in Women with Postmenopausal Osteoporosis, Bone, 30: 320-324.

4. Antundal, H. and Güvener, Ö. (2004). The Effect of Alendronate on Resorption of the Alveolar Bone Following Tooth Extraction, Int. J. Oral Maxillofac. Surg., 33: 286-293. 
5. Jahangari, L., Devlin, H., Ting, K. and Nishimura, I. (1998). Current Perspectives in Residual Ridge Remodelling and its Clinical Implications: A Review, J. Prosthet. Dent., 80: 224-237.

6. Pollähne, W., Pfeifer, M., Lazarescu, D. and Minne, H.W. (1996). Osteoporose - Bildgebende Diagnostik, Medizin. im Bild., 4: 37-44.

7. Becker, B.E., Becker, W., Ricci, A. and Geurs, N. (1998). A Prospective Clinical Trial of Endosseous Screw-shaped Implants Placed at the Time of Tooth Extraction without Augmentation, J. Periodontol., 69: 920-926.

8. Hürzeler, M.B., Quinones, C.R., Hutmacher, D. and Schupbach, P. (1997). Guide Bone Regeneration around Dental Implants in the Atrophic Alveolar Ridge using a Bioresorbable Barrier - An Experimental Study in the Monkey, Clin. Oral. Implants Res., 8: 323-331.

9. Caulier, H., Naert, I., Kalk, W. and Jansen, J.A. (1997). The Relationship of Some Histologic Parameters, Radiographic Evaluations, and Periotest Measurements of Oral Implants: An Experimental Animal Study, Int. J. Oral Maxillofac. Impl., 12: 380-386.

10. Hahn, E., Sonis, S., Gallagher, G. and Atwood, D. (1988). Preservation of the Alveolar Ridge with Hydroxyapatite-collagen Implants in Rats, J. Prosthet. Dent., 60: 729-734.

11. Zaffe, D., Bertoldi, C., Palumbo, C. and Consolo, U. (2002). Morphofunctional and Clinical Study on Mandibular Alveolar Distraction Osteogenesis, Clin. Oral Impl. Res., 13: 550-555.

12. Ajdukovic, Z., Najman, S., Djordjevic, Lj., Savic, V., Mihailovic, D., Ignjatovic, N. and Uskokovic, D. (2005). Repair of Bone Tissue Affected by Osteoporosis Hydroxyapatite-poly-l-lactide (HAp/PLLA) with and without Blood Plasma, J. Biomater. Appl., 20: 179-190.

13. Ignjatovic, N., Ajdukovic, Z. and Uskokovic, D. (2005). New Biocomposite [Biphasic Calcium Phosphate/Poly-DL-lactide-co-glycolide/Biostimulative Agent] Filler for Reconstruction of Bone Tissue Changed by Osteoporosis, J. Ma. Sci.: M. Med., 16: 616-626.

14. Nagano, M., Kitsugi, T., Nakamura, T., Kokubo, T. and Tanahashi, M. (1996). Bone Bonding Ability of an Apatite-coated Polymer Produced using a Biomimetic Method: A Mechanical and Histological Study in vivo. J. Biomed. Mater. Res., 31: 487-494.

15. Tanahashi, M., Yao, T., Kokubo, T., Minoda, M., Miyamoto, T., Nakamura, T. and Yamamuro, T. (1994). Apatite Coating on Organic Polymers by Biomimetic Process, J. Am. Ceram. Soc., 77: 2805-2808.

16. Fournier, E., Passirani, C., Montero-Menei, C.N. and Benoit, J.P. (2003). Biocompatibility of Implantable Synthetic Polymeric Drug Carriers: Focus on Brain Biocompatibility, Biomaterials, 24: 3311-3331.

17. Elgendy, H., Norman, M., Keaton, A. and Laurencin, C. (1993). Osteoblastlike Cell (MC3T3-E1) Proliferation on Bioerodible Polymers: An Approach towards the Development of a Bone-Bioerodible Polymer Composite Material, Biomaterials, 14: 263-268.

18. Ignjatovic, N., Ninkov, P., Ajdukovic, Z., Konstantinovic, V. and Uskokovic, D. (2005). Synthesis, Characterization and Application of Composite Biomaterials Biphasic Calcium Phosphate/Poly-dl-lactide-co-glycolide as 
Filler and Blocks for Reparation Hard Bone Tissue, Mater. Sci. Forum, 494: 519-524.

19. Tezal, M., Wactawski-Wende, J., Grossi, S., Ho, A., Dunford, R. and Genco, R. (2000). The Relationship between Bone Mineral Density and Periodontitis in Postmenopausal Women, J. Periodontol., 71: 1492-1498.

20. John, A., Varma, K.H. and Kumari, V.T. (2003). Surface Reactivity of Calcium Phosphate based Ceramics in a Cell Culture System, J. Biomater. Appl., 18: 63-78.

21. Sugar, A.W., Thielens, P., Stafford, G.D. and Wilins, M.J. (1995). Augmentation of the Atrophic Maxillary Alveolar Ridge with Hydroxylapatite Granules in Vicryl(Polyglactin) Knitted Tube and Simultaneous Open Vestibuloplasty, Br. J. Oral. \& Maxillofac. Surg., 33: 93-97.

22. Artzi, Z. and Nemcovsky, C. (1998). The Application of Deproteinized Bovine Bone Mineral for Ridge Preservation Prior to Implantation. Clinical and Histological Observations in a Case Report, J. Periodontol., 69: $1062-1067$.

23. Wiesen, M. and Kitzis, R. (1998). Preservation of the Alveolar Ridge at Implant Sides, Periodontol. Clin. Investig., 20: 17-20.

24. Malek, M. and Obwegeser, A.J. (2003). The Bioconvertible Osteosynthesis System - Result of a Prospective Clinical Study on Stability of Bimaxillary Surgery, J. Biomater. Appl., 18: 35-51.

25. Ulm, C., Kneissel, M., Schedle, A., Solar, P., Matejka, M., Schneider, B. and Donath, K. (1999). Characteristic Features of Trabecular Bone in Edentulous Maxillae, Clin. Oral Implants Res., 10: 459-467.

26. Anselme, K. (2000). Osteoblast Adhesion on Biomaterials, Biomaterials, 21: $667-681$.

27. LeGeros, R.Z. (2002). Properties of Osteoconductive Biomaterials: Calcium Phosphates, Clin. Orthop. Relat. Res., 395: 81-98.

28. Riis, B.J. (1991). Biochemical Markers and Bone Turnover in Diagnosis and Assessment of Therapy, Ann. J. Med., 91: 64-68. 